\title{
Association of US State Implementation of Newborn Screening Policies for Critical Congenital Heart Disease With Early Infant Cardiac Deaths
}

\author{
Rahi Abouk, PhD, Scott D. Grosse, PhD, Elizabeth C. Ailes, PhD, MPH, and Matthew E. \\ Oster, MD, MPH \\ William Paterson University, Cotsakos College of Business, Wayne, New Jersey (Abouk); Centers \\ for Disease Control and Prevention, National Center on Birth Defects and Developmental \\ Disabilities, Atlanta, Georgia (Grosse, Ailes, Oster); Children's Healthcare of Atlanta, Emory \\ University School of Medicine, Atlanta, Georgia (Oster)
}

\section{Abstract}

\begin{abstract}
IMPORTANCE-In 2011, critical congenital heart disease was added to the US Recommended Uniform Screening Panel for newborns, but whether state implementation of screening policies has been associated with infant death rates is unknown.
\end{abstract}

\begin{abstract}
OBJECTIVE-To assess whether there was an association between implementation of state newborn screening policies for critical congenital heart disease and infant death rates.
\end{abstract}

DESIGN, SETTING, AND PARTICIPANTS-Observational study with group-level analyses. A difference-in-differences analysis was conducted using the National Center for Health Statistics' period linked birth/infant death data set files for 2007-2013 for 26546503 US births through June 30, 2013, aggregated by month and state of birth.

EXPOSURES-State policies were classified as mandatory or nonmandatory (including voluntary policies and mandates that were not yet implemented). As of June 1, 2013, 8 states had implemented mandatory screening policies, 5 states had voluntary screening policies, and 9 states had adopted but not yet implemented mandates.

Corresponding Author: Rahi Abouk, PhD, Cotsakos College of Business, William Paterson University, 300 Pompton Rd, Wayne, NJ 07470 (aboukr@wpunj.edu).

Conflict of Interest Disclosures: All authors have completed and submitted the ICMJE Form for Disclosure of Potential Conflicts of Interest. Dr Grosse reports participation in a study tour organized by the Newborn Foundation. No other disclosures are reported.

Disclaimer: The findings and conclusions in this report are those of the authors and do not necessarily represent the official position of the CDC.

Additional Contributions: We thank Kim Van Naarden Braun, PhD, formerly of the CDC and the New Jersey Department of Health; Jeff Hudson, MA, of the American Academy of Pediatrics; Jill Glidewell, MSN, of the CDC; and Marci Sontag, PhD, of the University of Colorado School of Public Health for helping to clarify effective dates of screening policies. We also thank Tiffany Colarusso, MD, MPH, of the CDC; Andrew Ewer, MD, of the University of Birmingham; Suzanne Gilboa, PhD, of the CDC; John Iskander, MD, MPH, of the CDC; Cora Peterson, PhD, of the CDC; Annamarie Saarinen, MA, of the Newborn Foundation; and Phoebe Thorpe, MD, MPH, of the CDC for helpful comments. None of those individuals received compensation for their assistance.

Author Contributions: Dr Abouk had full access to all of the data in the study and takes responsibility for the integrity of the data and the accuracy of the data analysis. Concept and design: All authors. Acquisition, analysis, or interpretation of data: Abouk, Ailes, Oster.Drafting of the manuscript: Abouk, Grosse.Critical revision of the manuscript for important intellectual content: All authors.Statistical analysis: Abouk, Grosse, Ailes.Administrative, technical, or material support: Abouk, Ailes, Oster.Supervision: Abouk, Oster. 
MAIN OUTCOMES AND MEASURES-Numbers of early infant deaths (between 24 hours and 6 months of age) coded for critical congenital heart disease or other/unspecified congenital cardiac causes for each state-month birth cohort.

RESULTS-Between 2007 and 2013, there were 2734 deaths due to critical congenital heart disease and 3967 deaths due to other/unspecified causes. Critical congenital heart disease death rates in states with mandatory screening policies were 8.0 (95\% CI, 5.4-10.6) per 100000 births $(\mathrm{n}=37)$ in 2007 and 6.4 (95\% CI, 2.9-9.9) per 100000 births $(\mathrm{n}=13)$ in 2013 (for births by the end of July); for other/unspecified cardiac causes, death rates were 11.7 (95\% CI, 8.6-14.8) per 100000 births in $2007(\mathrm{n}=54)$ and $10.3(95 \%$ CI, 5.9-14.8) per 100000 births $(\mathrm{n}=21)$ in 2013. Early infant deaths from critical congenital heart disease through December 31, 2013, decreased by $33.4 \%$ (95\% CI, 10.6\%-50.3\%), with an absolute decline of 3.9 (95\% CI, 3.6-4.1) deaths per 100000 births after states implemented mandatory screening compared with prior periods and states without screening policies. Early infant deaths from other/unspecified cardiac causes declined by $21.4 \%$ (95\% CI, 6.9\%-33.7\%), with an absolute decline of 3.5 (95\% CI, 3.2-3.8) deaths per 100000 births. No significant decrease was associated with nonmandatory screening policies.

CONCLUSIONS AND RELEVANCE-Statewide implementation of mandatory policies for newborn screening for critical congenital heart disease was associated with a significant decrease in infant cardiac deaths between 2007 and 2013 compared with states without these policies.

Congenital heart disease, which occurs in 800 per 100000 births, ${ }^{1}$ accounted for $6 \%$ of US infant deaths during 1999-2006. ${ }^{2}$ Critical congenital heart disease, a subset of 12 phenotypes or defects with a high likelihood of presenting with low blood oxygen saturation (hypoxemia), occurs in 200 per 100000 births. ${ }^{1,3}$ The rationale for screening is that timely detection can reduce the risk of an apparently healthy infant with critical congenital heart disease being discharged home and experiencing a potentially fatal crisis. ${ }^{4}$ If not diagnosed in a timely manner, particularly before the patent ductus arteriosus closes at a few days of life, infants with these defects often die. Surgical treatments are available, and survival to adulthood in the modern era surpasses $82 \%$ in the United States despite surgical complications and long-term cardiac and noncardiac comorbidities. ${ }^{5}$

Routine screening using pulse oximetry in the United States is typically conducted around 24 hours after birth. ${ }^{3}$ Following a positive screening result, diagnostic tests are conducted to determine a cause of hypoxemia. ${ }^{6}$ Echocardiography is routinely done to identify a cardiac cause, and other tests such as chest x-ray, complete blood cell count, and blood culture may be ordered to identify noncardiac causes. Specificity of screening at or after 24 hours is high and false positives uncommon (approximately $0.05 \%$, 4 ). The sensitivity of screening to detect critical congenital heart disease is variable; a meta-analysis estimated a sensitivity of $78 \%,{ }^{7}$ but sensitivity may range from $36 \%$ to $92 \%$ depending on the phenotype. ${ }^{8}$ Modeling studies of the potential number of cases detected by screening for critical congenital heart disease in the United States suggest that screening could be cost-effective. 8,9

Critical congenital heart disease was added to the US Recommended Uniform Screening Panel for newborns in September 2011. ${ }^{10,11}$ Subsequently, most US states implemented policies recommending or requiring screening. ${ }^{11,12}$ As of August 9, 2016, 48 states had 
either enacted legislation or adopted regulations relating to pulse oximetry screening of newborns. ${ }^{13}$

This study evaluated the association between state screening policies during 2011-2013 and infant deaths attributable to critical congenital heart disease, hypothesizing that states that implemented screening policies would experience greater declines in death rates than other states and that this association would be strongest in states with mandatory screening.

\section{Methods}

\section{Study Design}

This was an observational study with group-level analyses. Pooled cross-sectional timeseries data with a difference-in-differences analytic approach were used to evaluate changes in critical congenital heart disease and other congenital heart disease deaths in states implementing screening policies between August 1, 2011, and June 1, 2013. This design controlled for both secular trends in infant cardiac deaths and time-invariant state-specific effects. ${ }^{14}$ Given that deaths are not independent within a state over time, clustered standard errors were estimated to prevent overrejection of the null hypothesis. ${ }^{15}$

Because the data were anonymized, the human subjects contact at the Centers for Disease Control and Prevention (CDC) National Center on Birth Defects and Developmental Disabilities determined that the study did not require human subjects protections in accordance with federal regulations.

\section{Data}

The period linked birth/infant death data set files from the National Center for Health Statistics at the CDC containing live births from 2007 through 2013 were used. The 2013 data were the most recent available data at the time of analysis. These files contain all infant ( $<1$ year of age) deaths in a given year linked to the corresponding birth certificates for infants born in the same year or the previous year. The database includes information from both the birth certificate (eg, state and month of birth) and death certificate (eg, age at death and underlying and multiple causes of death).

\section{Policies}

A screening policy can be a regulation, guidance document, or legislation and can be mandatory or nonmandatory. For enactment dates of nonmandatory policies, the month during which a policy was enacted was treated as the beginning of the exposure to the policy; all infants born in that month were classified as exposed and all infants born in months before any screening policy was adopted were treated as unexposed. Months for which the implementation date of a mandatory screening policy occurred on the first day of the month were classified as exposed. Because mandates typically have a lead time before being implemented, with gradual adoption of screening by hospitals, births during months after a mandate had been enacted but not yet implemented were classified as exposed to nonmandatory screening policies, the same as months during which explicitly nonmandatory screening policies were in place. 
Enactment and implementation dates were identified by review of legislation, regulations, or guidance documents or descriptions of those policies when available, supplemented by a source of information on critical congenital heart disease screening policy dates in months (Table 1). ${ }^{11}$

\section{Outcome Measures}

In the period linked birth/infant death data set used in this study, approximately $90 \%$ of infant deaths due to critical congenital heart disease occurred in the first 6 months after birth. The main outcome variables were the numbers of early infant (from 24 hours to $<6$ months of age) deaths due to either critical congenital heart disease or other/unspecified congenital heart defects based on International Statistical Classification of Diseases and Related Health Problems, Tenth Revision (ICD-10) codes Q20.0-Q26.9 for underlying cause of death (eTable 1 in the Supplement). Deaths coded for patent or persistent foramen ovale (Q21.1) or patent ductus arteriosus (Q25.0) if the infant was born preterm were excluded because these are considered normal conditions of prematurity. ${ }^{16}$ To identify deaths coded for critical congenital heart disease, $I C D$ - 10 codes associated with 12 phenotypes were used, although some codes may include noncritical congenital heart disease malformations (eTable 1). ${ }^{17}$ All deaths not coded for critical congenital heart disease were classified as "other" congenital cardiac deaths. Births from January 1, 2007, to June 30, 2013, were included in the analysis; births in the second half of 2013 were excluded to ensure that all deaths prior to 6 months of age were identified.

\section{Statistical Analysis}

Data were aggregated by birth month and year and state of birth. Because not all infant death records could be linked to the corresponding birth certificate, weights included in the data set were used in the aggregation to adjust for the percentage of death certificates linked to birth certificates, which varied slightly by age at death and state. Early infant deaths due to critical congenital heart disease and other/unspecified congenital heart defects among infants born in states that at the time of birth had policies in effect that mandated screening were compared with cohorts of infants born in states without screening policies in place at the time of birth.

Because the outcome variable of interest was a count (number of deaths due to critical congenital heart disease or other/unspecified defects in a given state-month-year), a Poisson regression model was used. Deviance and Pearson goodness-of-fit tests were conducted, and large $P$ values provided no evidence against selecting a Poisson regression model. The log number of monthly births in a state was included as an offset along with time-varying state characteristics, state and year-month fixed effects to capture time-variant factors in each state, and time-specific factors common across all states (eTable 2 in the Supplement). Adjusted percentage declines in early infant death rates were calculated by taking the exponential of the regression coefficients (and the associated 95\%confidence interval) and subtracting 1.

The difference-in-differences identification strategy relies on the assumption of parallel pretreatment trends in treated and control states. This assumption in models was tested by 
including an interaction term between time and a dummy variable for whether states enacted mandatory screening. ${ }^{14}$

Stata version 14.0 (Stata Corp) was used for all analyses. Results for regression coefficients other than interaction terms were reported as significant based on a .05 level of significance using a 2 -sided test; $P<.10$ was used to assess interaction terms.

\section{Sensitivity and Falsification Analyses}

In sensitivity analyses, 3 alternative age periods for deaths were used: 24 hours to 12 months of age, birth to age 6 months, and birth to 12 months. The analysis also was modified to exclude deaths among very preterm births ( $<32$ weeks of gestation). In addition, separate coefficients were estimated for 2 early-adopter states that implemented screening mandates in August 2011 and January 2012 and 6 states that later implemented mandates from August 2012 through May 2013.

Falsification or placebo analyses were conducted by repeating the primary analysis with outcome measures presumed to be unrelated to the policy. The leading causes of infant deaths other than congenital malformations were grouped into 4 categories: sudden infant death syndrome, bacterial sepsis, maternal and placental complications, and disorders of short gestation and low birth weight (ICD-10 codes listed in eTable 1 in the Supplement). Each was defined as deaths occurring between 24 hours and 6 months after birth. Neonatal sepsis can be detected through pulse oximetry screening, and deaths from sepsis could therefore potentially be affected by critical congenital heart disease screening ${ }^{18}$; the other 3 categories were assumed to be unrelated to screening.

\section{Results}

Between August 31, 2011, and June 1, 2013, 8 states implemented mandatory critical congenital heart disease screening policies. Five states adopted nonmandatory screening policies and 9 states adopted mandatory screening policies during that period but had not yet implemented the mandates by June 1, 2013 (Table 1).

The timing of implementation of screening policies was first compared with trends in death rates at a national level. Less than $1 \%$ of infants born during 2011 were born in states with screening mandates, which increased to 5.6\% in 2012 and 16.3\% in 2013. Between 2007 and 2013, there were 2734 deaths from critical congenital heart disease and 3967 deaths from other/unspecified congenital cardiac causes. For the period 2007-2012, there was a modest average annual exponential decline in the rates of early infant death due to critical congenital heart disease by $2.8 \%$ per year (from 11.1 [95\% CI, 10.1-12.1] per $100000[\mathrm{n}=$ 478] births in 2007 to 9.7 [95\% CI, 8.7-10.6] per 100000 [ $n=382$ ] in 2012) (Table 2). Similarly, the rate of other/unspecified defects declined by an exponential $1.8 \%$ per year (from 14.8 [95\% CI, 13.7-16.0] per 100000 [ $\mathrm{n}=640$ ] births in 2007 to 13.4 [95\% CI, 12.214.5] per 100000 [ $n=529]$ in 2012). In contrast, between 2012 and 2013, rates of death due to critical congenital heart disease and other/unspecified cardiac causes decreased by $16.8 \%$ to $8.0(95 \% \mathrm{CI}, 7.2-8.9)$ per $100000(\mathrm{n}=316)$ and by $13.2 \%$ to $11.6(95 \% \mathrm{CI}, 10.6-12.7)$ per $100000(n=457)$, respectively. The critical congenital heart disease and other/ 
unspecified cardiac death rates for births in states with no screening policy did not change over time. In 2013, the critical congenital heart disease death rate was 10.6 (95\% CI, 8.6$12.5)$ per 100000 births $(\mathrm{n}=117)$ and the other/unspecified cardiac death rate was 14.6 (95\% CI, 12.416.9) per 100000 births $(\mathrm{n}=162)$ (eTable 3 in the Supplement).

States that implemented mandatory critical congenital heart disease screening policies during the study period had mean critical congenital heart disease death rates before adoption that were lower than in states without any screening policy or that adopted only nonmandatory policies (Table 3 and Figure). However, critical congenital heart disease death rates were not trending downward in states that adopted mandatory policies prior to the adoption of mandates, and there was no decrease in critical congenital heart disease deaths during the intervening months between adoption and implementation. In contrast, a mean $50 \%$ decrease in critical congenital heart disease death rates occurred following implementation. The adoption of nonmandatory screening policies was not associated with a reduction in critical congenital heart disease deaths.

Relative to states with no mandatory screening policies, the mean adjusted relative decline in critical congenital heart disease deaths during months with mandatory screening policies in place was $33.4 \%$ (95\% CI, $10.6 \%-50.3 \%$ ), with an absolute decrease of 3.9 (95\% CI, 3.64.1) deaths per 100000 births (Table 4 and eTable 4 in the Supplement). The mean relative decrease in other/unspecified cardiac deaths was $21.4 \%$ (95\% CI, 6.9\%-33.7\%), with an absolute decline of 3.5 (95\% CI, 3.2-3.8) deaths per 100000 births. These were derived from the Poisson regression coefficients in the regression models (eTable 2 in the Supplement). The adjusted declines in death rates for birth cohorts born under nonmandatory policies relative to birth cohorts in states with no screening policies were smaller and not statistically significant (eTable 2).

No evidence of nonparallel trends was found in critical congenital heart disease and other cardiac infant deaths prior to the adoption of mandatory screening policies. The coefficients for the interaction terms of time and screening mandates were essentially zero $(-0.001 ; 95 \%$ CI, -0.008 to 0.006 for critical congenital heart disease deaths) (eTable 5 in the Supplement).

In a sensitivity analysis that allowed for differential associations with early and late adoption of screening mandates, the magnitude of the reduction in critical congenital heart disease deaths was smaller in the 2 states (New Jersey and Indiana) that implemented mandates prior to July 2012. The point estimate of the relative reduction in critical congenital heart disease deaths in those 2 states was $19.7 \%$ (95\% CI, 3.1\%-37.7\%), and the absolute decrease was 1.9 (95\% CI, 1.5-2.3) per 100000 births. In comparison, the mean relative decrease in the remaining 6 states (Connecticut, Delaware, Maryland, New Hampshire, Tennessee, and Virginia) was 53.5\% (95\% CI, 36.0\%-66.3\%) (Table 4), and the absolute decrease was 4.6 (95\% CI, 4.2-5.0) per 100000 births (eTable 4 in the Supplement).

In other sensitivity analyses, results for the percentage of critical congenital heart disease deaths avoided by mandatory screening policies were robust to different temporal cut-offs for deaths. Point estimates of the reduction ranged from $28.4 \%$ to $30.7 \%$ of all infant critical 
congenital heart disease deaths relative to the baseline (Table 4). The absolute decreases ranged from 3.2 (95\% CI, 3.0-3.4) per 100000 births to 4.1 (95\% CI, 3.9-4.4) per 100000 births for infant deaths prior to 6 months (eTables 4 and 6 in the Supplement). The estimated reductions in other congenital cardiac deaths were statistically significant in analyses of deaths from birth to 6 or 12 months.

Results of the falsification analyses showed no association of mandatory or nonmandatory critical congenital heart disease screening policies with changes in any other type of early infant deaths (eTable 7 in the Supplement).

\section{Discussion}

Implementation of policies requiring critical congenital heart disease screening by June 1 , 2013, in 8 states was associated with a 33.4\% reduction in early infant deaths due to recognized critical congenital heart disease. The reduction in early infant deaths due to critical congenital heart disease including deaths occurring in the first 24 hours was 30.7\%; the smaller relative reduction in that analysis likely reflects that screening at 24 hours cannot avert deaths during the first 24 hours. The relative reduction in critical congenital heart disease deaths exceeded 50\% for 6 states implementing mandates from July 1, 2012, to June 1,2013 . These findings support the policies implemented by states to require critical congenital heart disease screening.

The goal of critical congenital heart disease screening is to reduce the number of deaths due to missed or late diagnoses. Previously published US estimates suggested that pulse oximetry could prevent 20 to 100 infant deaths from critical congenital heart disease each year. ${ }^{5,19,20}$ For example, a California study reported a mean of 10 deaths per year during 1989-2004 among infants with missed critical congenital heart disease diagnoses, equivalent to 70 preventable deaths each year in the United States. ${ }^{20}$ A one-third reduction from the baseline of 350 to 380 critical congenital heart disease infant deaths per year would imply 120 fewer deaths per year if mandatory screening were implemented nationwide. A previous cost-effectiveness analysis that assumed that 20 deaths would be averted each year by universal critical congenital heart disease screening in the United States calculated an incremental cost-effectiveness ratio of $\$ 40385$ per life-year gained (in 2011 US dollars). ${ }^{9}$ The present results suggest a lower cost per life-year gained.

In addition to the estimated decrease in deaths classified as due to critical congenital heart disease, there was a significant reduction in other early infant cardiac deaths. This reduction may represent cases of critical congenital heart disease that were given a nonspecific ICD-10 code on the death certificate or cases of noncritical cardiac defects that might have been detected as a result of screening. ${ }^{6,18}$

This study has several strengths. First, the difference-indifferences study design controls for underlying trends in factors influencing infant cardiac deaths. Second, falsification studies demonstrated that mandatory critical congenital heart disease screening policies were unrelated to the occurrence of early infant deaths attributed to the leading noncardiac causes of infant mortality in the United States. If the analysis had found significant associations of 
critical congenital heart disease screening policies with infant deaths that are not causally related to hypoxemia, that would have called into question the meaningfulness of the associations found with cardiac deaths. One group of noncardiac early infant deaths, associated with pneumonia or sepsis, is related to hypoxemia. ${ }^{18,21}$ Although the present study found no significant reduction in deaths coded for pneumonia or sepsis associated with US policies to screen for critical congenital heart disease around 24 hours after birth, an association between pulse oximetry screening and a reduction in neonatal deaths from pneumonia or sepsis cannot be ruled out if such screening were conducted immediately after birth or in countries where the mortality burden is larger.

Because almost all US states have adopted policies recommending or requiring screening for critical congenital heart disease, ${ }^{13}$ the findings of this study are not intended to inform further state policies. Nonetheless, retrospective evaluations of regulatory policies are important to validate the projected benefits of policies. ${ }^{22}$ In addition, lessons learned from policy evaluations in one country can inform policy decisions in other countries. In particular, the findings have implications for countries that are considering the possible adoption of a policy to routinely screen newborns for critical congenital heart disease. ${ }^{23}$

\section{Limitations}

This study had limitations. First, the classification of deaths using ICD-10 codes may not be exact (eg, code Q20.3 may include other types of transposition of the great arteries); therefore, a few deaths classified as due to critical congenital heart disease may have been associated with other malformations. Second, the study may not have included all important confounders in the regression modeling analyses. Third, the estimates were imprecise due to small numbers of infant critical congenital heart disease deaths by state and month and the small number of states with fully implemented screening mandates by June 1, 2013. Therefore, the results should be interpreted with caution, and replication with additional years of data is needed.

Fourth, there was a lack of information on actual screening practices by hospitals within a state because many states do not require hospitals to report screening to state health departments. ${ }^{12}$ Not all hospitals necessarily screened for critical congenital heart disease after screening mandates had been implemented, and hospitals in states without a screening policy may have screened. The study design may be subject to the "ecological fallacy" because actual screening practices were not observed. However, this was an ecological analysis of screening policies, not screening practices, and the study design was appropriate for the study purpose. Screening policies may not necessarily entirely account for the effect of screening practices. For example, screening mandates might result in increased clinical detection of infants with critical congenital heart disease as a consequence of increased clinical awareness of the importance of prompt detection.

Fifth, although efforts were made to ascertain exact dates of implementation of screening policies, there was a lack of documentation for some states. To the extent that uptake of screening was incomplete, despite the existence of mandates, the estimates in this study may have understated the association with mandates that are effectively enforced. Conversely, hospitals may have implemented screening voluntarily in the absence of a state policy, with 
some hospitals implementing screening well before $2011 .{ }^{24}$ Widespread screening in states without screening policies would lessen the estimated effectiveness of screening policies. The large decreases in death rates in 2013 might represent the wider implementation of mandated screening as well as voluntary screening practices.

Sixth, there was a lack of information on the timing of critical congenital heart disease diagnoses. Such information would be needed to assess the effect of screening policies on the occurrence of late or missed critical congenital heart disease diagnoses. To conduct comprehensive evaluation of the effects of critical congenital heart disease screening policies, state based birth defects registries linked to screening records could be useful. ${ }^{12}$

Seventh, lack of state-level information was lacking on the availability of pediatric cardiology care facilities or the practice of prenatal critical congenital heart disease diagnosis. Both of these variables could influence numbers of critical congenital heart disease deaths and the effects of screening policies on deaths. ${ }^{25,26}$ Prenatal detection for many types of critical congenital heart disease remains low in the United States. ${ }^{8}$ Improvements in prenatal diagnosis of critical congenital heart disease can be expected to diminish the effect of screening on critical congenital heart disease death rates by reducing the numbers of children with undiagnosed disease that could be diagnosed as a result of postnatal screening. The same caveat applies to improvements in clinical care.

\section{Conclusions}

Statewide implementation of mandatory policies for newborn screening for critical congenital heart disease was associated with a significant decrease in infant cardiac deaths between 2007 and 2013 compared with states without these policies.

\section{Supplementary Material}

Refer to Web version on PubMed Central for supplementary material.

\section{References}

1. Reller MD, Strickland MJ, Riehle-Colarusso T, Mahle WT, Correa A. Prevalence of congenital heart defects in metropolitan Atlanta, 1998-2005. J Pediatr. 2008; 153(6):807-813. [PubMed: 18657826]

2. Gilboa SM, Salemi JL, Nembhard WN, Fixler DE, Correa A. Mortality resulting from congenital heart disease among children and adults in the United States, 1999 to 2006. Circulation. 2010; 122(22):2254-2263. [PubMed: 21098447]

3. Kemper AR, Mahle WT, Martin GR, et al. Strategies for implementing screening for critical congenital heart disease. Pediatrics. 2011; 128(5):e1259-e1267. [PubMed: 21987707]

4. Mahle WT, Newburger JW, Matherne GP, et al. American Heart Association Congenital Heart Defects Committee of the Council on Cardiovascular Disease in the Young, Council on Cardiovascular Nursing, and Interdisciplinary Council on Quality of Care and Outcomes Research; American Academy of Pediatrics Section on Cardiology and Cardiac Surgery, and Committee on Fetus and Newborn. Role of pulse oximetry in examining newborns for congenital heart disease: a scientific statement from the American Heart Association and American Academy of Pediatrics. Circulation. 2009; 120(5):447-458. [PubMed: 19581492]

5. Oster ME, Lee KA, Honein MA, Riehle-Colarusso T, Shin M, Correa A. Temporal trends in survival among infants with critical congenital heart defects. Pediatrics. 2013; 131(5):e1502-e1508.

[PubMed: 23610203] 
6. Oster ME, Aucott SW, Glidewell J, et al. Lessons learned from newborn screening for critical congenital heart defects. Pediatrics. 2016; 137(5):e20154573. [PubMed: 27244826]

7. Thangaratinam S, Brown K, Zamora J, Khan KS, Ewer AK. Pulse oximetry screening for critical congenital heart defects in a symptomatic newborn babies: a systematic review and meta-analysis. Lancet. 2012; 379(9835):2459-2464. [PubMed: 22554860]

8. Ailes EC, Gilboa SM, Honein MA, Oster ME. Estimated number of infants detected and missed by critical congenital heart defect screening. Pediatrics. 2015; 135(6):1000-1008. [PubMed: 25963011]

9. Peterson C, Grosse SD, Oster ME, Olney RS, Cassell CH. Cost-effectiveness of routine screening for critical congenital heart disease in US newborns. Pediatrics. 2013; 132(3):e595-e603. [PubMed: 23918890]

10. Martin GR, Beekman RH III, Mikula EB, et al. Implementing recommended screening for critical congenital heart disease. Pediatrics. 2013; 132(1):e185-e192. [PubMed: 23776113]

11. Glidewell J, Olney RS, Hinton C, et al. Centers for Disease Control and Prevention. State legislation, regulations, and hospital guidelines for newborn screening for critical congenital heart defects-United States, 2011-2014. MMWR Morb Mortal Wkly Rep. 2015; 64(23):625-630. [PubMed: 26086632]

12. Grosse SD, Riehle-Colarusso T, Gaffney M, et al. CDC Grand Rounds: newborn screening for hearing loss and critical congenital heart disease. MMWR Morb Mortal Wkly Rep. 2017; 66(33): 888-890. [PubMed: 28837548]

13. American Academy of Pediatrics. [Accessed October 25, 2017] Newborn Screening for Critical Congenital Heart Disease (CCHD)—2016 State Actions. 2016. https://www.aap.org/en-us/ Documents/2016_CCHD_Newborn_Screening_State_Actions.pdf

14. Dimick JB, Ryan AM. Methods for evaluating changes in health care policy: the difference-indifferences approach. JAMA. 2014; 312(22):2401-2402. [PubMed: 25490331]

15. Bertrand M, Duflo E, Mullainathan S. How much should we trust differences-in-differences estimates? Q J Econ. 2004; 119(1):249-275.

16. Simeone RM, Oster ME, Hobbs CA, Robbins JM, Collins RT, Honein MA. Population-based study of hospital costs for hospitalizations of infants, children, and adults with a congenital heart defect, Arkansas 2006 to 2011. Birth Defects Res A Clin Mol Teratol. 2015; 103(9):814-820. [PubMed: 26069215]

17. National Birth Defects Prevention Network Birth Defects Definitions Group. [Accessed November 10, 2016] Appendix 3.1: Birth Defects Descriptions for NBDPN Core, Recommended, and Extended Conditions. 2015. https://www.nbdpn.org/docs/ Appendix_3_1_BirthDefectsDescriptions2015_2016DEC14.pdf

18. Singh A, Rasiah SV, Ewer AK. The impact of routine predischarge pulse oximetry screening in a regional neonatal unit. Arch Dis Child Fetal Neonatal Ed. 2014; 99(4):F297-F302. [PubMed: 24646619]

19. Govindaswami B, Jegatheesan P, Song D. Oxygen saturation screening for critical congenital heart disease. Neoreviews. 2012; 13(12):e724-e731.

20. Chang RK, Gurvitz M, Rodriguez S. Missed diagnosis of critical congenital heart disease. Arch Pediatr Adolesc Med. 2008; 162(10):969-974. [PubMed: 18838650]

21. Ewer AK, Martin GR. Newborn pulse oximetry screening: which algorithm is best? Pediatrics. 2016; 138(5):e20161206. [PubMed: 27940777]

22. Grosse SD, Waitzman NJ, Romano PS, Mulinare J. Reevaluating the benefits of folic acid fortification in the United States: economic analysis, regulation, and public health. Am J Public Health. 2005; 95(11):1917-1922. [PubMed: 16195513]

23. Ismail AQ, Cawsey M, Ewer AK. Newborn pulse oximetry screening in practice. Arch Dis Child Educ Pract Ed. 2017; 102(3):155-161. [PubMed: 27530240]

24. Koppel RI, Druschel CM, Carter T, et al. Effectiveness of pulse oximetry screening for congenital heart disease in a symptomatic newborns. Pediatrics. 2003; 111(3):451-455. [PubMed: 12612220]

25. Quartermain MD, Pasquali SK, Hill KD, et al. Variation in prenatal diagnosis of congenital heart disease in infants. Pediatrics. 2015; 136(2):e378-e385. [PubMed: 26216324]

26. Hill GD, Block JR, Tanem JB, Frommelt MA. Disparities in the prenatal detection of critical congenital heart disease. Prenat Diagn. 2015; 35(9):859-863. [PubMed: 25989740] 


\section{Key Points}

\section{Question}

Were mandatory state newborn screening policies for critical congenital heart disease using pulse oximetry associated with a decrease in infant cardiac deaths?

\section{Findings}

In this observational study conducted between 2007 and 2013 including approximately 27 million US births, state adoption of a mandatory screening policy was associated with a statistically significant decline of $33.4 \%$ in the death rate due to critical congenital heart disease compared with states without such policies.

\section{Meaning}

Mandatory screening policies were associated with a reduction in infant deaths due to critical congenital heart disease. 

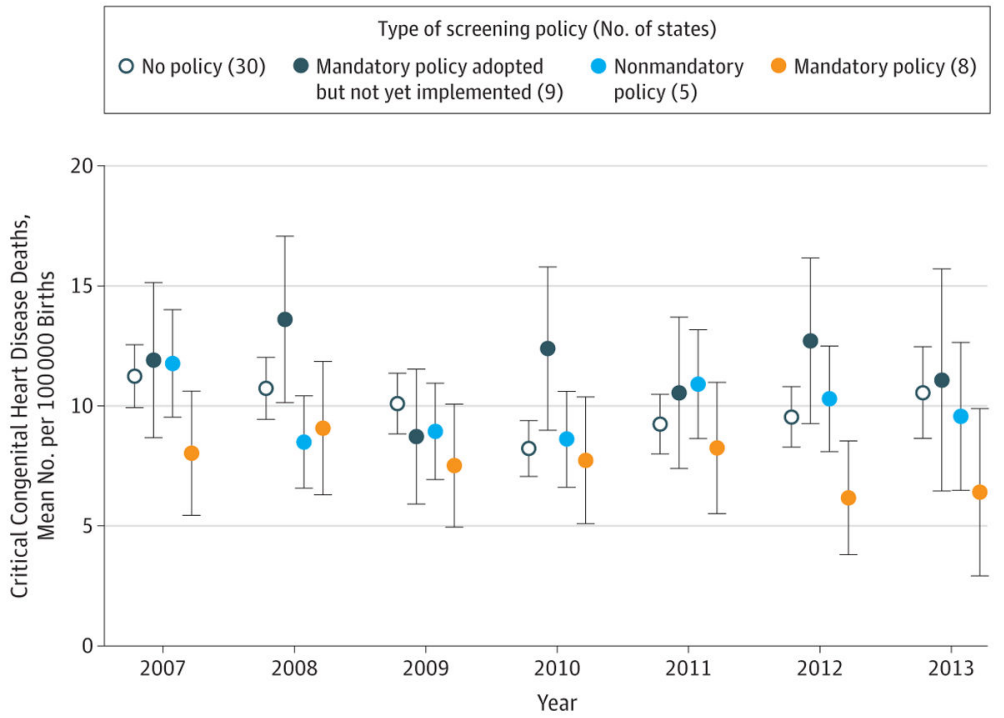

Figure.

Mean Critical Congenital Heart Disease Early Infant Death Rates by Year, 2007-2013, for States With No Screening Policy, States With Mandatory Screening Policy Not Yet Implemented and Implemented by June 1, 2013, and States With Only Nonmandatory Screening Policies as of June 1, 2013

Error bars indicate 95\% CIs. State policies were assessed as of June 1, 2013. Observations are from all 50 states and the District of Columbia; Alabama had a nonmandatory policy but enacted a mandatory policy later so is included in both groups. 


\section{Table 1}

Implementation Dates (or Months) for States With Policies on Newborn Critical Congenital Heart Disease Screening Enacted by June 1, 2013 ${ }^{a}$

\begin{tabular}{|c|c|c|}
\hline State & Enactment Date & Implementation Date \\
\hline \multicolumn{3}{|l|}{ Mandatory } \\
\hline Connecticut & May $2012^{b}$ & January 1, 2013 \\
\hline Delaware & May 1,2013 & May 1, 2013 \\
\hline Indiana & May $2011^{b}$ & January 1,2012 \\
\hline Maryland & May 19, 2011 & September 1, 2012 \\
\hline New Hampshire & June $2012^{b}$ & August 11, 2012 \\
\hline New Jersey & June 2, 2011 & August 31, 2011 \\
\hline Tennessee & March 1, 2012 & May 31, 2013 \\
\hline West Virginia & April 5, 2012 & September 1, 2012 \\
\hline \multicolumn{3}{|l|}{ Nonmandatory } \\
\hline Alabama & February 22, 2012 & February 22, 2012 \\
\hline California & September 15, 2012 & July 1,2013 \\
\hline Iowa & August $2012^{b}$ & August $2012^{b}$ \\
\hline Massachusetts & May 10, 2013 & May 10, 2013 \\
\hline Pennsylvania & December 1,2012 & March 1, 2013 \\
\hline \multicolumn{3}{|c|}{ Mandatory enacted but not yet implemented } \\
\hline Alabama & May 17, 2013 & June 21,2013 \\
\hline Arkansas & April 5, 2013 & July 1,2015 \\
\hline Kentucky & March 19, 2013 & January 1, 2014 \\
\hline Minnesota & May 23, 2013 & August $2013^{b}$ \\
\hline North Carolina & May 8, 2013 & July 25, 2014 \\
\hline North Dakota & April $2013^{b}$ & August $2013^{b}$ \\
\hline Oklahoma & April 18, 2013 & July 1,2013 \\
\hline South Dakota & $\operatorname{March} 2013^{b}$ & July $2013^{b}$ \\
\hline Utah & $\operatorname{March} 2013^{b}$ & October 1, 2014 \\
\hline
\end{tabular}

aEnactment: for legislation when enacted into law (usually date signed by governor). Implementation: date when policy became legally effective at the level of the birthing center.

$b_{\text {No information on specific dates could be identified. }}$ 


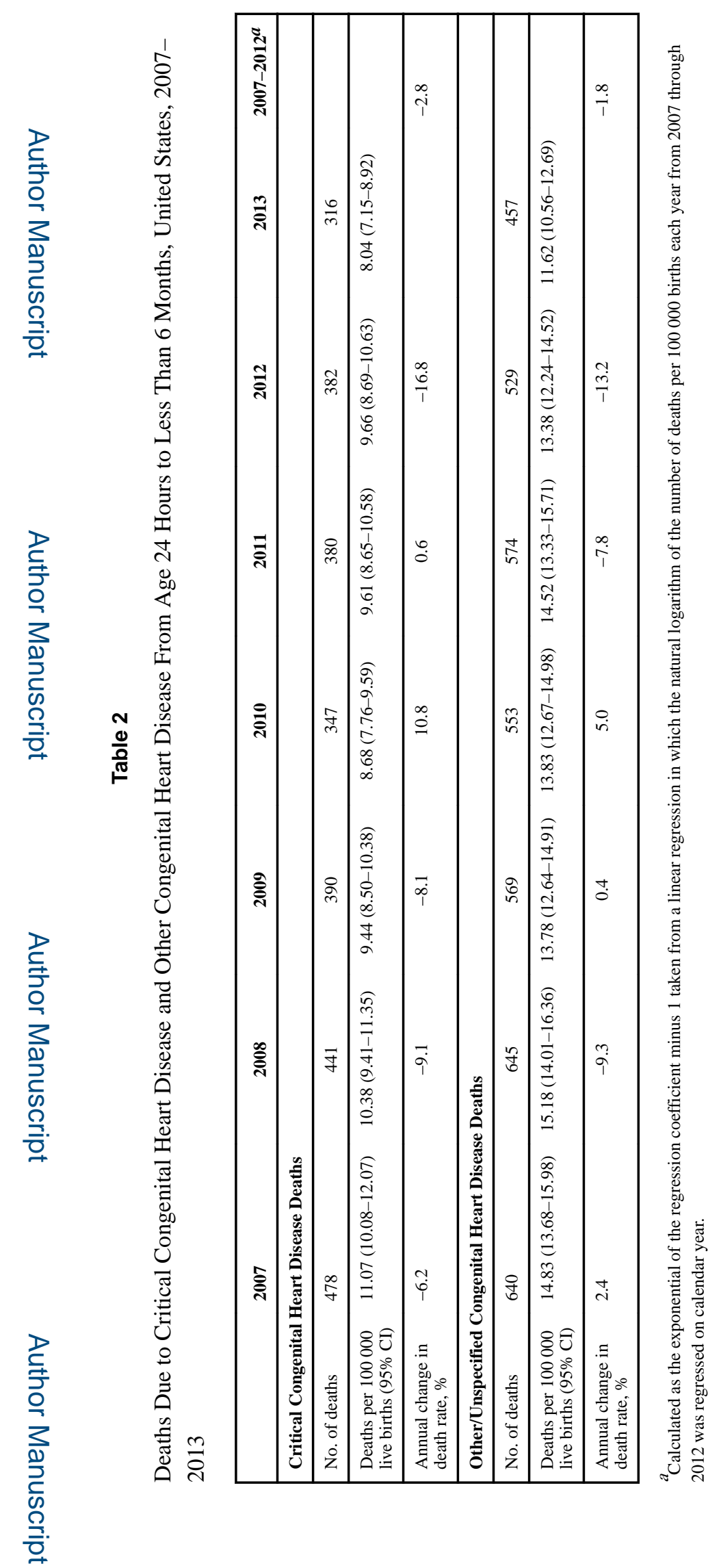

JAMA. Author manuscript; available in PMC 2018 December 05. 


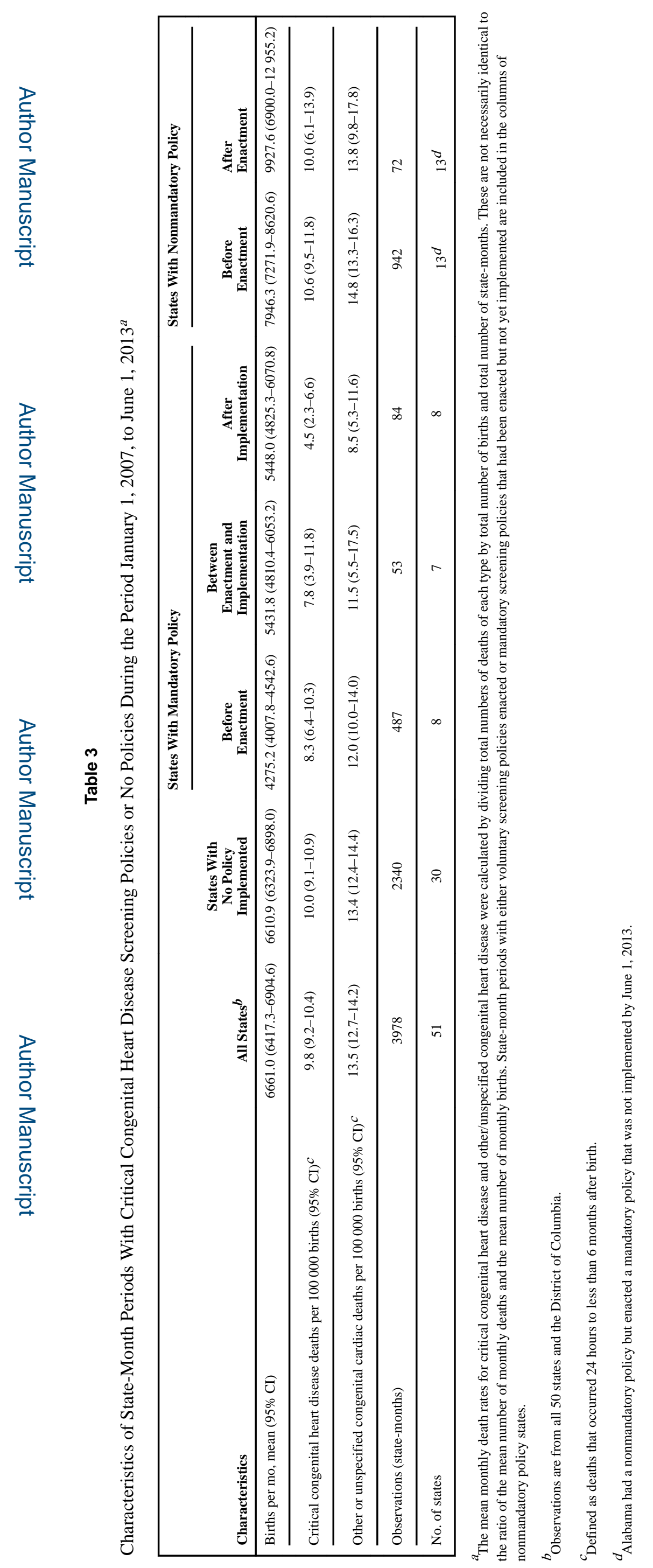




\section{Table 4}

Adjusted Percentage Declines in Rates of Deaths Due to Critical Congenital Heart Disease and Other Congenital Heart Disease Associated With State Mandatory Screening Policies, 2011-2013 ${ }^{a}$

\begin{tabular}{|c|c|c|}
\hline \multirow[b]{2}{*}{ Age Range of Deaths } & \multicolumn{2}{|c|}{ Decline in Death Rate, \% (95\% CI) } \\
\hline & $\begin{array}{l}\text { Critical Congenital Heart } \\
\text { Disease Deaths }\end{array}$ & $\begin{array}{l}\text { Other or Unspecified Congenital } \\
\text { Heart Disease Deaths }\end{array}$ \\
\hline $24 \mathrm{~h}$ to $<6 \mathrm{mo}$ & $33.4(10.6$ to 50.3$)$ & $21.4(6.9$ to 33.7$)$ \\
\hline \multicolumn{3}{|c|}{$\begin{array}{l}\text { Sensitivity analyses of timing of mandate (age at death } 24 \mathrm{~h} \text { to } \\
<6 \mathrm{mo} \text { ) }\end{array}$} \\
\hline Implemented Aug 1, 2011-June 30, 2012 & $19.7(3.1$ to 37.1$)$ & $21.7(8.7$ to 32.9$)$ \\
\hline Implemented July 1, 2012-June 1, 2013 & $53.6(36.0$ to 66.3$)$ & $21.0(0.3$ to 37.4$)$ \\
\hline \multicolumn{3}{|c|}{$\begin{array}{l}\text { Sensitivity analyses of timing of deaths (screening implemented } \\
\text { Aug 1,2011-June } 1,2013 \text { ) }\end{array}$} \\
\hline Birth to $<6 \mathrm{mo}$ & $30.7(9.3$ to 47.1$)$ & $27.0(15.1$ to 37.3$)$ \\
\hline Birth to $<12$ mo & $28.4(8.5$ to 44.0$)$ & 17.9 (3.0 to 30.6$)$ \\
\hline $24 \mathrm{~h}$ to $<12 \mathrm{mo}$ & $30.5(12.9$ to 44.5$)$ & $11.2(-4.8$ to 24.9$)$ \\
\hline $24 \mathrm{~h}$ to $<6 \mathrm{mo}$, restricted to infants born at $>32 \mathrm{wk}$ & $29.5(5.0$ to 50.1$)$ & $20.1(2.3$ to 34.7$)$ \\
\hline
\end{tabular}

${ }^{a}$ Percentage declines are derived from Poisson regression coefficients. Those regression models include all explanatory variables listed in eTable 2 in the Supplement in addition to state and month-year fixed effects. Numbers in parentheses are clustered confidence intervals at state level to capture non independence of observations in the same state. Poisson regression coefficients for the association with deaths from 24 hours to less than 6 months of age are presented in eTable 2 in the Supplement. 